\title{
Effect of cooling rate on morphology and type of vanadium-containing phases in $\mathrm{Al}-10 \mathrm{~V}$ master alloy
}

\author{
Qing-feng Zhu', ${ }^{1,}$, 'Yi Meng ${ }^{1,3}$, Yan-lei Kang', ${ }^{1,}$, Shu-ping Kong', Yang-peng Ou', Yu-bo Zuo' \\ 1. Key Laboratory of Electromagnetic Processing of Materials, Ministry of Education, Northeastern University, Shenyang 110819, China; \\ 2. School of Materials Science and Engineering, Northeastern University, Shenyang 110819, China; \\ 3. School of Mechanical and Materials Engineering, North China University of Technology, Beijing 100144, China
}

\begin{abstract}
Effects of cooling rates on the morphology, sizes and species of primary vanadium-containing phases in Al-10V master alloys were investigated. The results show that the primary vanadium-containing phases with different morphologies and compositions present in $\mathrm{Al}-10 \mathrm{~V}$ master alloys at different cooling rates with the pouring temperature of $1,170{ }^{\circ} \mathrm{C}$. When the Al-10V master alloy is solidified in the refractory mold at a cooling rate of $2{ }^{\circ} \mathrm{C} \cdot \mathrm{s}^{-1}$, the vanadium-containing phases are mainly plate-like $\mathrm{Al}_{10} \mathrm{~V}$ phases, with the average size of $100.0 \mu \mathrm{m}$ in the center and $93.2 \mu \mathrm{m}$ at the edge of the ingot. When the master alloy is solidified in the graphite mold at a cooling rate of $24.3^{\circ} \mathrm{C} \cdot \mathrm{s}^{-1}$, the primary vanadium-containing phases are dendritic $\mathrm{Al}_{3} \mathrm{~V}$ phases, with the average length of $297.0 \mu \mathrm{m}$ for the first dendrite in the center and $275.0 \mu \mathrm{m}$ at the edge of the ingot. The secondary dendrite arm spacing (SDAS) is $9.5 \mu \mathrm{m}$ in the center and $9.3 \mu \mathrm{m}$ at the edge of the ingot, respectively. When the solidification is carried out in the copper mould at a cooling rate of $45.7^{\circ} \mathrm{C} \cdot \mathrm{s}^{-1}$, the primary vanadium-containing phases are also $\mathrm{Al}_{3} \mathrm{~V}$ phases but with smaller size, compared with that prepared at the cooling rate of $24.3^{\circ} \mathrm{C} \cdot \mathrm{s}^{-1}$. As a result, the average length is $190.0 \mu \mathrm{m}$ for the first dendrite in the center and $150.0 \mu \mathrm{m}$ at the edge of the ingot. The SDAS is $9.8 \mu \mathrm{m}$ in the center and $4.4 \mu \mathrm{m}$ at the edge of the ingot, respectively.
\end{abstract}

Key words: AI-V master alloy; cooling rate; vanadium-containing phase; solidification

CLC numbers: TG146.21 Document code: A Article ID: 1672-6421(2019)05-300-07

$\mathrm{T}$ The addition of trace elements is an effective way to improve the microstructures and mechanical properties of aluminum alloys ${ }^{[1-2]}$. Some trace elements are added into the aluminum liquid in the form of master alloys due to their high melting point, high loss, and slow dissolution rates ${ }^{[2]}$. As a result, the mass loss of aluminum caused by the high temperature can be avoided, and the high yielding rate can be available.

Vanadium (V) element can affect the microstructures and properties of aluminum alloys. Maria Teresa Di Giovanni et al. ${ }^{[3]}$ found that adding 0.1 wt. $\% \mathrm{~V}$ into the A356 aluminum alloy would increase the amounts of $\pi-\mathrm{Al}_{8} \mathrm{FeMg}_{3} \mathrm{Si}_{6}$ and $\mathrm{Mg}_{2} \mathrm{Si}$ phases, but limit the improvement of mechanical properties. Cangji Shin

\section{*Yi Meng}

Male, Ph.D., Lecturer. His research mainly focuses on the theories and technology of aluminum alloys by multi-components alloying. His academic research has led to the publication of more than 20 papers.

E-mail: mengyi@ncut.edu.cn.

Received: 2019-03-28; Accepted: 2019-05-30 et al. ${ }^{[4-8]}$ studied that the near spherical V-containing dispersoids in large number and a few rod-like $\mathrm{Al}_{21} \mathrm{~V}_{2}$ phases were formed in the 7150 aluminum alloys with different $\mathrm{V}$ addition of 0.11 wt. $\%, 0.15$ wt. $\%$ and 0.19 wt. $\%$ after homogenization. However, the coarse $\mathrm{Al}_{21} \mathrm{~V}_{2}$ phases formed once the $\mathrm{V}$ content reached as high as 0.19 wt. $\%{ }^{[4]}$. And complex cubic $\mathrm{Al}_{21} \mathrm{~V}_{2}$ phase was also designated as $\mathrm{Al}_{10} \mathrm{~V}$ phase ${ }^{[9]}$. Elhadari et al. ${ }^{[10]}$ discovered that the formation of $\mathrm{Al}_{3} \mathrm{Zr}$ and $\mathrm{Al}_{3}(\mathrm{Zr}, \mathrm{V})$ phases improved both the yield strength and fatigue life of the alloy.

Therefore, many references studied the effects of trace vanadium on the microstructures and mechanical properties of different commercial aluminum alloys. But the adding method of trace vanadium into the aluminum alloys was not involved in these references. It is well known that the melting point of vanadium is as high as $1,929{ }^{\circ} \mathrm{C}$, and the solubility of vanadium in aluminum is extremely low ${ }^{[9]}$. $\mathrm{V}$ is usually difficult to be added into the aluminum alloys successfully. So, it is necessary to focus on the adding method of $\mathrm{V}$ into 
aluminum alloys.

One effective way to add the trace $\mathrm{V}$ element into the aluminum molten liquid might be in the form of Al-V master alloys. Meng Y et al. ${ }^{[1-12]}$ and Cangji Shin et al. ${ }^{[4]}$ found that the type and shape of V-phases in Al-V master alloys determined the microstructures and mechanical properties of aluminum alloy. So, the effect of different V-phases in Al-V master alloys on the microstructures and mechanical properties of commercial aluminum alloys should be considered separately.

The melting and casting parameters for the preparation of Al-V master alloys, such as the V content, melting temperature, holding time and cooling speed, have the ability to influence the formation of different V-phases directly. Kenney D J et al. ${ }^{[13]}$ studied the effect of $\mathrm{V}$ content on the as-cast microstructures of Al-V alloys prepared at different temperatures $\left(710-1,100{ }^{\circ} \mathrm{C}\right)$ and found $\mathrm{V}$-containing phases with different structures and shapes. Yi Meng et al. ${ }^{[11-12]}$ studied that the $\mathrm{Al}_{3} \mathrm{~V}$ and $\mathrm{Al}_{10} \mathrm{~V}$ phases could be formed in Al-4V alloys in different melting and casting processes. Therefore, the foundational theories about the effects of melting parameters on the formation of different $\mathrm{V}$-phases during the preparation of Al-V master alloys should be established firstly.

At present, Al-10wt.\%V alloy is widely applied in industry, but few references report the preparation of Al-10wt.\%V mater alloys. So the effects of different casting parameters on the $\mathrm{V}$-containing phases in the $\mathrm{Al}-10 \mathrm{wt} . \% \mathrm{~V}$ master alloys need to be studied systematically. The cooling rates affected the type and shape of V-phases in Al-V master alloys significantly based on our researches before, but few references concerned about this aspect systematically either. In this work, the effect of cooling rates on the as-cast microstructures of $\mathrm{Al}-10 \mathrm{wt} . \% \mathrm{~V}$ master alloys was studied.

\section{Experiment methods}

Al-10wt.\%V master alloy with the weight of $\sim 4.5 \mathrm{~kg}$ was melted at $1,170{ }^{\circ} \mathrm{C}$ in a graphite crucible located in a medium frequency induction furnace and then it was kept at $1,170{ }^{\circ} \mathrm{C}$ for $20 \mathrm{~min}$. The molten alloy was poured into different molds at $1,170{ }^{\circ} \mathrm{C}$. These molds were made with pure copper, graphite and refractory, respectively. These three molds were all the same shape and the same sizes, as shown in Fig. 1. The multiple-path temperature measurement instrument produced by HIOKI Company was used to obtain the cooling rates during solidification of the alloys. Figure 1 shows that the thermocouple was located in the center of ingot with a height of $15 \mathrm{~mm}$ above the bottom of mold. The collection cycle of HIOKI data collector was set to $0.01 \mathrm{~s}$.

The as-cast samples for X-ray diffraction (XRD), optical microscopy (OM) and scanning electron microscopy (SEM) were cut from the center of the ingots (with $15 \mathrm{~mm}$ distance from the bottom of mold). X-ray diffraction (XRD) was used to identify vanadium-containing phases in Al-10wt.\%V master alloys, with the scanning speed of $4^{\circ} \cdot \mathrm{min}^{-1}$ and the scanning range of $20^{\circ}-110^{\circ}$. The microstructures of samples were

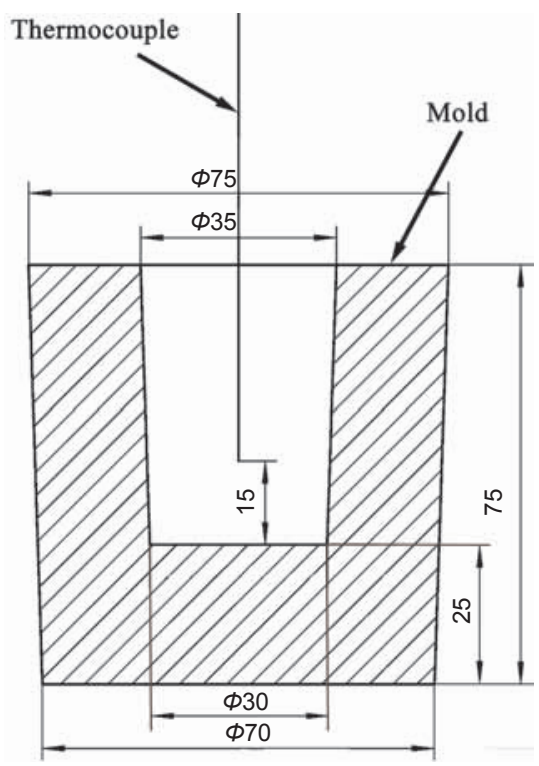

Fig. 1: Schematic diagram of casting mold

electrochemically etched with a solution of 10 vol.\% perchloric acid and 90 vol.\% anhydrous ethanol at $30 \mathrm{~V}$ for $15 \mathrm{~s}$, and then observed on a LEICA D35578 type optical microscope. Image Pro Plus software was used to count the sizes of V-containing phases according to the optical microstructures. A SIGMA 500 field emission scanning electron microscope (SEM) equipped with energy dispersive analytical X-ray (EDAX) was used to observe the 3-Dimensional microstructure characteristics of the V-containing phases in ingots after being etched deeply by a solution of 20 vol. $\% \mathrm{NaOH}$.

\section{Results}

\subsection{Cooling curves obtained in different molds}

Figure 2 shows the cooling curves of the alloys in the copper mold, graphite mold and refractory mold during the solidification of Al-10wt.\% V alloys. It can be found that the temperature drops down dramatically after the molten alloys are poured into these molds at $1,170{ }^{\circ} \mathrm{C}$. The platforms are present in all cooling curves when the temperature drops to

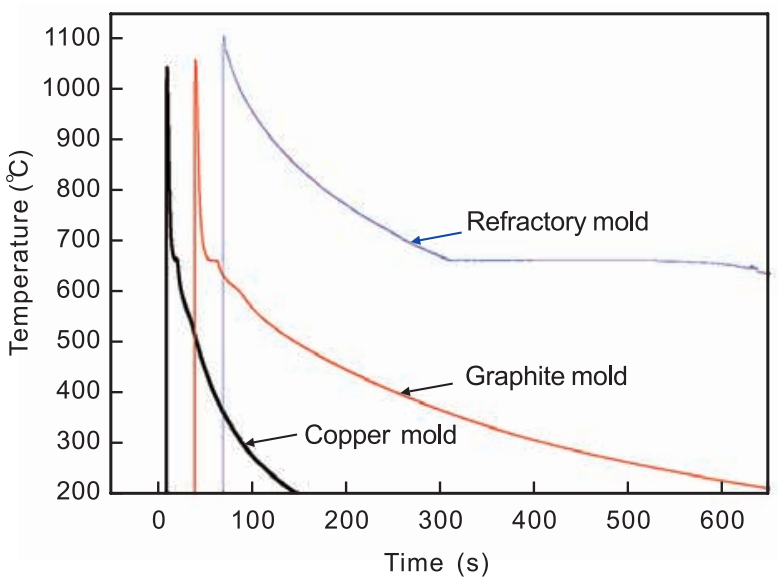

Fig. 2: Time-temperature curves of $\mathrm{Al}-10 \mathrm{wt} . \% \mathrm{~V}$ alloys in different molds 
$\sim 660^{\circ} \mathrm{C}$. But the durations of platforms in the cooling curves are significantly different with the shortest for the copper mold and the longest for the refractory mold. This is due to the great difference of cooling rates for these three molds, i.e. the cooling rates of the alloys in the copper mold, graphite mold and refractory mold are $45.7,24.3$ and $2.0^{\circ} \mathrm{C} \cdot \mathrm{s}^{-1}$, respectively.

\subsection{XRD analysis results}

Figure 3 shows the XRD patterns of Al-10wt.\%V alloys

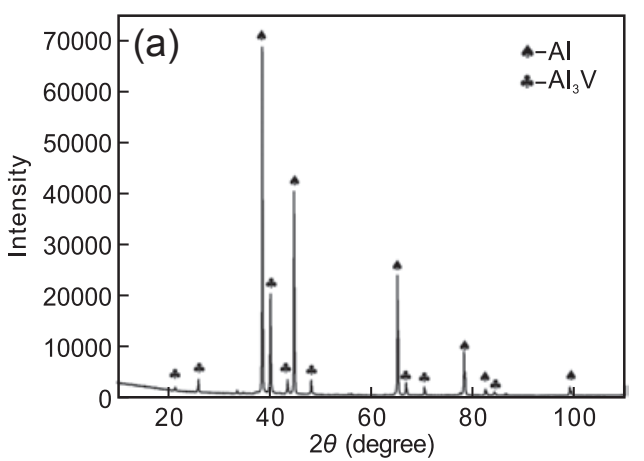

prepared in copper mold, graphite mold and refractory mold. Primary $\mathrm{Al}_{3} \mathrm{~V}$ phases and $\mathrm{Al}$-matrix exist in the ingots prepared by the copper mold and graphite mold, as shown in Figs. 3 (a) and (b). However, $\mathrm{Al}_{10} \mathrm{~V}$ phases and Al-matrix are discovered in the ingot prepared in the refractory mold. Therefore, it can be concluded that the $\mathrm{Al}_{3} \mathrm{~V}$ phases can be formed when the cooling rate is greater than $24.3{ }^{\circ} \mathrm{C} \cdot \mathrm{s}^{-1}$. On the contrary, the cooling rate of $2.0^{\circ} \mathrm{C} \cdot \mathrm{s}^{-1}$ will result in the formation of $\mathrm{Al}_{10} \mathrm{~V}$ phases.
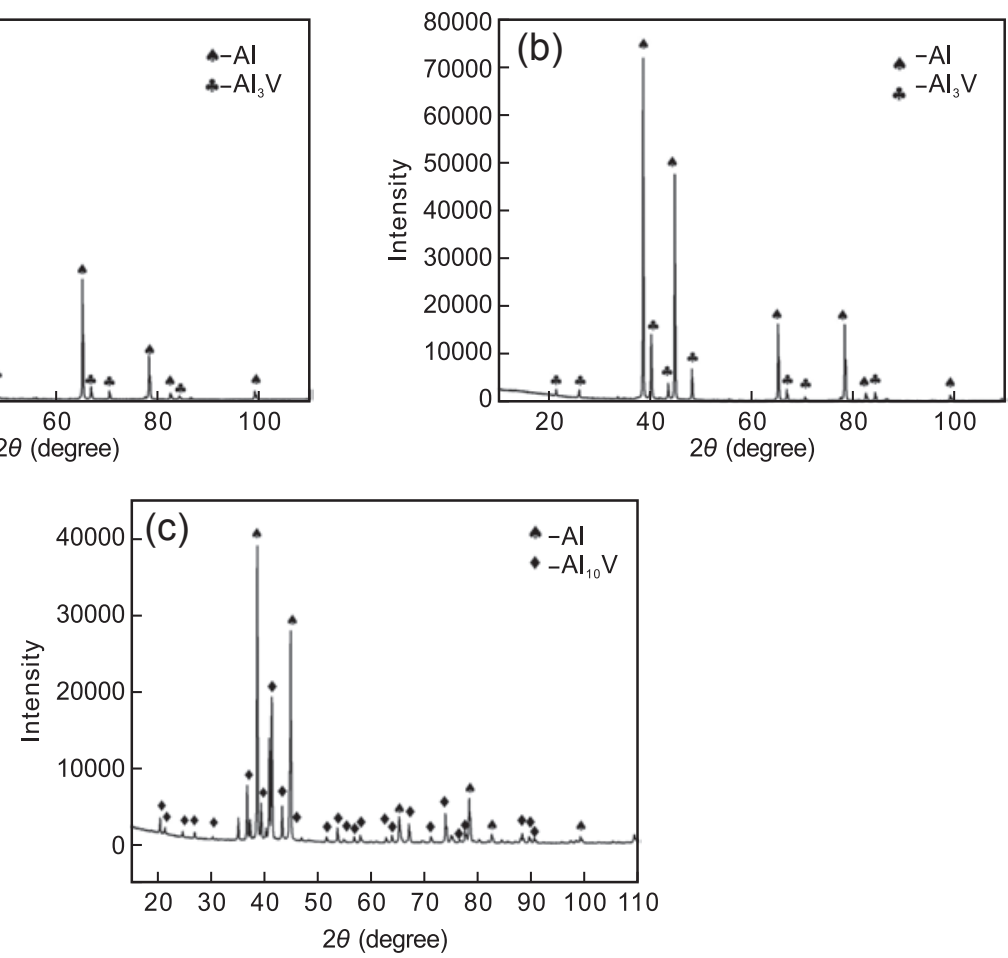

Fig. 3: XRD patterns of Al-10wt.\%V master alloys prepared in different molds: (a) copper mold; (b) graphite mold; (c) refractory mold

\subsection{D microstructures of vanadium- containing phases prepared at different cooling rates}

Figure 4 illustrates the SEM microstructures of the centers of Al$10 \mathrm{wt} . \% \mathrm{~V}$ alloy ingots prepared in copper mold, graphite mold and refractory mold, obtaining the morphologies of $\mathrm{V}$-containing phases for 3D imaging. The V-containing phases with dendritic morphology (phase A) are present when the alloy is prepared in the copper mold, as shown in Fig. 4 (a). The differences of $\mathrm{V}$-containing phases in sizes are great. Primary dendrite grows along the direction of fastest decrease in temperature after the nucleation of V-containing phases, such as the red arrows shown in Fig. 4 (a), and the length of some primary dendrites reach as long as $350 \mu \mathrm{m}$. The secondary dendrite is formed on both sides of primary dendrite in the form of arborization. Similarly, the length of some secondary dendrites is large as well along $<110>$ crystal orientation ${ }^{[9,14]}$, and the tertiary dendrite is formed in the same way. The morphology of V-containing phases (phase B) shown in Fig. 4 (b) is also arborization when the ingot is prepared in the graphite mold with a lower cooling rate, compared with the cooling rate of the copper mold. However, secondary dendritic arm spacing of the V-containing phases increases dramatically. Additionally, the preferred growth orientation of most secondary dendrites is symmetrical and a few secondary dendrites grow long, while the morphology of V-containing phases (phase C) changes significantly to platelike and grows obviously when the ingot is prepared by the refractory mold with the lowest cooling rate [Fig. 4 (c)].

The EDAX analysis results of A, B and $\mathrm{C}$ phases shown in Fig. 4 are indicated in Figs. 5 (a), (b) and (c), respectively, identifying the types of V-containing phases with different morphologies. It can be found from Figs. 4 and 5 that phases with different morphologies belong to V-containing phases and their compositions are different as well. Figures 5(a) and (b) illustrate that the atomic ratio of $\mathrm{Al}$ and $\mathrm{V}(\mathrm{Al}: \mathrm{V})$ of both $\mathrm{A}$ and $\mathrm{B}$ phases with dendrite morphology shown in Figs. 4 (a) and (b) approximately equal to 3:1. Therefore, they should be $\mathrm{Al}_{3} \mathrm{~V}$ phases based on the XRD results in Figs. 3 (a) and (b). However, the atomic ratio of $\mathrm{Al}$ and $\mathrm{V}(\mathrm{Al}$ : $\mathrm{V}$ ) of $\mathrm{C}$ phase with plate-like morphology in Fig. 4 (c) approximately equals to 10:1 according to Fig. 5 (c). As a result, it can be inferred that phase $\mathrm{C}$ should be $\mathrm{Al}_{10} \mathrm{~V}$ phase based on the XRD result in Fig. 3 (c). 

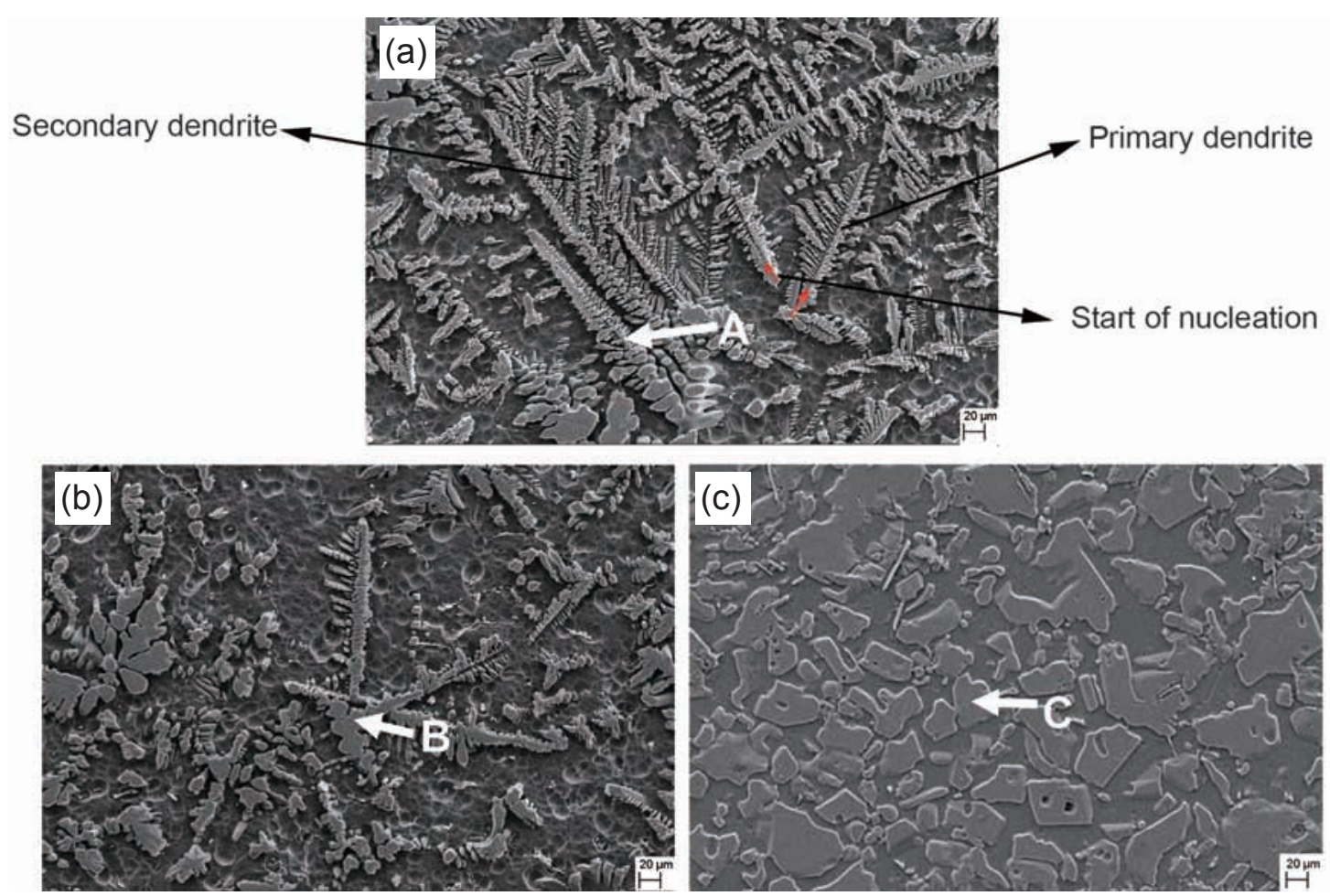

Fig. 4: SEM microstructures of $\mathrm{Al}-10 \mathrm{wt} . \% \mathrm{~V}$ alloys in center of ingots prepared in different molds: (a) copper mold; (b) graphite mold; (c) refractory mold
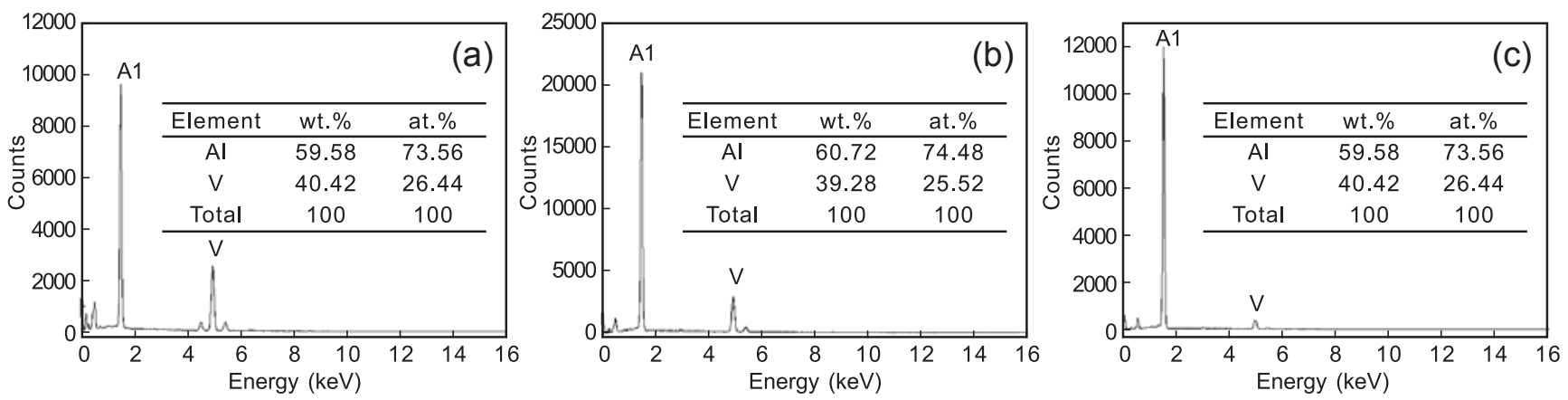

Fig. 5: EDAX analysis results of phases A (a), phase B (b) and phase C (c) in Fig. 4

\subsection{Microstructure}

Figure 6 shows the microstructures in the center and at the edge of the ingots of Al-10wt.\% $\mathrm{V}$ master alloys prepared in different molds. $\mathrm{Al}_{3} \mathrm{~V}$ phases with a dendritic pattern are visible in the ingots prepared in both the copper mold and the graphite mold as shown in Figs. 6 (a)-(d), while $\mathrm{Al}_{10} \mathrm{~V}$ phases with plate morphology are formed in the ingot prepared in the refractory mold as shown in Figs. 6 (e) and (f). The size of $\mathrm{V}$-containing phases in the center of the ingot is different from that of $\mathrm{V}$-containing phases at the edge of ingot. The mean sizes of $\mathrm{Al}_{3} \mathrm{~V}$ phases in the major axis direction are $150.0 \mu \mathrm{m}$ and $190.0 \mu \mathrm{m}$ for the samples cut from the edge and from the center of the ingot prepared in the copper mold, and the corresponding secondary dendritic arm spacings (SDASs) are $4.4 \mu \mathrm{m}$ and $9.8 \mu \mathrm{m}$, respectively. However, the mean sizes of $\mathrm{Al}_{3} \mathrm{~V}$ phases in the major axial direction are $275.0 \mu \mathrm{m}$ (edge) and $297.0 \mu \mathrm{m}$ (center) for the samples prepared in the graphite mold, and the corresponding SDASs are $9.3 \mu \mathrm{m}$ and $9.5 \mu \mathrm{m}$, respectively. The mean sizes of $\mathrm{Al}_{10} \mathrm{~V}$ phases are $93.2 \mu \mathrm{m}$ (edge) and $100.0 \mu \mathrm{m}$ (center) for the samples prepared in the refractory mold. Additionally, the area fractions of $\mathrm{V}$-containing phases in the samples are also quite different as shown in Figs. 6 (b), (d) and (f). The area fractions of $\mathrm{Al}_{3} \mathrm{~V}$ phases in the center of the ingots prepared in the copper mold and graphite mold are about $35.5 \%$ and $37.3 \%$, respectively, while that of $\mathrm{Al}_{10} \mathrm{~V}$ phases in the center of the ingot prepared in the refractory mold is $59.9 \%$.

\section{Discussion}

\subsection{Formation of $\mathrm{Al}_{3} \mathrm{~V}$ phase and $\mathrm{Al}_{10} \mathrm{~V}$ phase}

In this work, the effects of cooling rates on the types and morphologies of $\mathrm{V}$-containing phases in alloys prepared at $1,170{ }^{\circ} \mathrm{C}$ were studied. Based on the Al-V binary equilibrium phase diagram ${ }^{[9]}$, the liquidus temperature of Al-10wt.\%V master alloy is about $1,160{ }^{\circ} \mathrm{C}$. So, $\mathrm{V}$ is dissolved into molten 

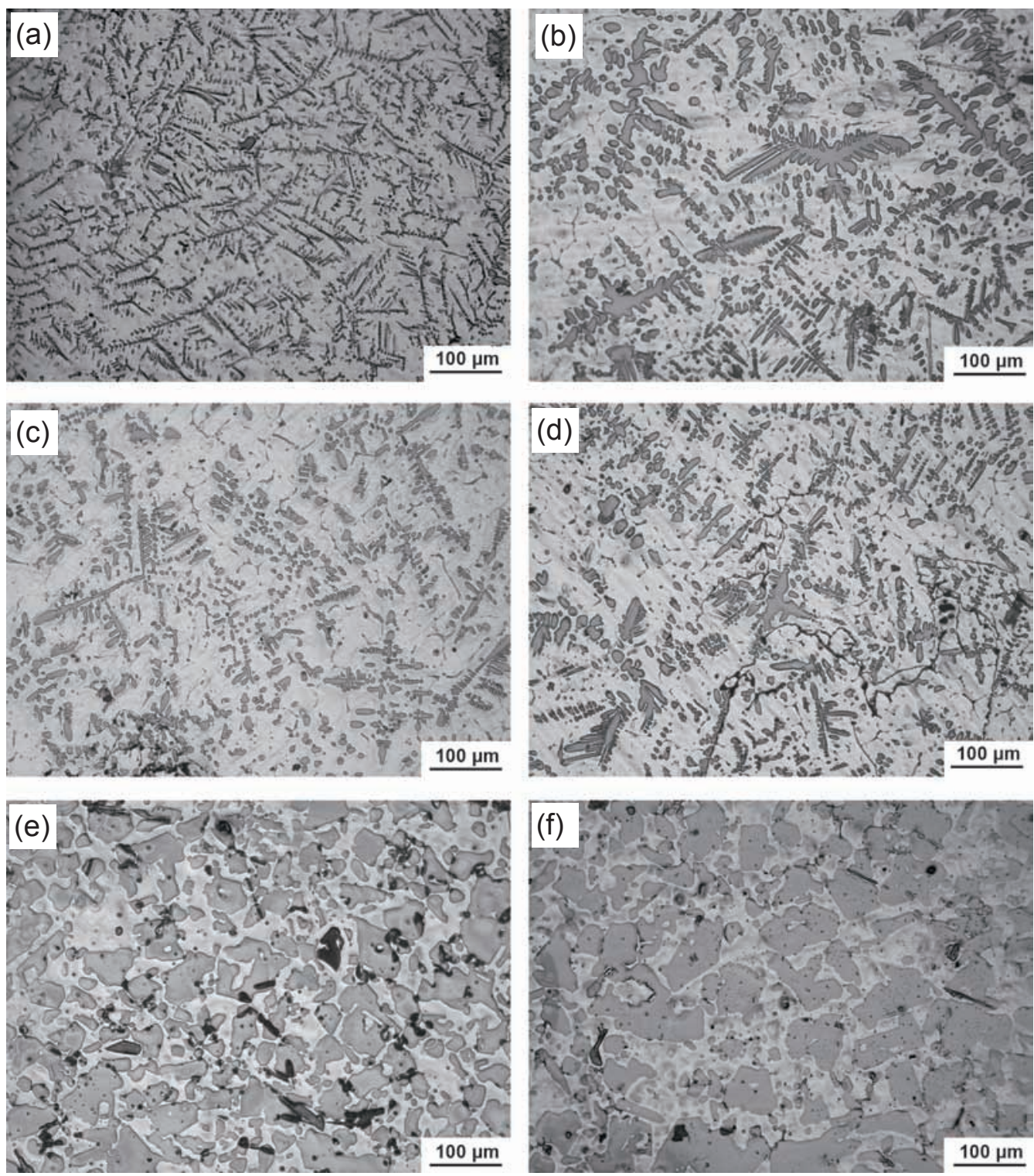

Fig. 6: Microstructures of V-containing phases in Al-10wt.\%V alloys prepared in different molds at location of center and edge of ingots, respectively: (a) copper mold, edge; (b) copper mold, center; (c) graphite mold, edge; (d) graphite mold, center; (e) refractory mold, edge; (f) refractory mold, center

aluminum totally after being held at $1,170{ }^{\circ} \mathrm{C}$ for $20 \mathrm{~min}$. Primary $\mathrm{Al}_{3} \mathrm{~V}$ phases form firstly with the temperature of the molten alloy dropping during solidification. The formation of $\mathrm{Al}_{3} \mathrm{~V}$ phase contains processes of the nucleation and growth. The morphology and size of these primary $\mathrm{Al}_{3} \mathrm{~V}$ phases should be affected by cooling rates, their preferential orientation, their growth rates and $\mathrm{V}$ concentration gradient at the solidification front of $\mathrm{Al}_{3} \mathrm{~V}$ phases ${ }^{[12]}$. When the cooling rate is high, the rates of both nucleation and growth of $\mathrm{Al}_{3} \mathrm{~V}$ phases in molten metal are great, as a result of the significant nucleation of $\mathrm{Al}_{3} \mathrm{~V}$ phases. The phases will grow along the preferred orientation when some specific orientation is just the opposite direction of heat transfer (direction of temperature gradient), and the number of $\mathrm{V}$ is large enough in this direction as shown in Fig. 4. Conversely, the growth of $\mathrm{Al}_{3} \mathrm{~V}$ phases will not be available along the directions in which the temperature gradient and $\mathrm{V}$ concentration distribution cannot meet the requirements. The growth of $\mathrm{Al}_{3} \mathrm{~V}$ phases along the preferential orientation stops in this direction once $\mathrm{V}$ at the solidification front forms other $\mathrm{Al}_{3} \mathrm{~V}$ phases nearby. Furthermore, the amount of nucleation in the molten metal increases by increasing the cooling rates, and as a result of decrease of $\mathrm{Al}_{3} \mathrm{~V}$ phases in size. Therefore, it can be concluded that the size of $\mathrm{Al}_{3} \mathrm{~V}$ phase formed in the copper mold with higher cooling rate is smaller than that of $\mathrm{Al}_{3} \mathrm{~V}$ phase in the corresponding position of the ingot prepared in the graphite mold. Besides, the size of $\mathrm{Al}_{3} \mathrm{~V}$ phase at the edge is also smaller than that in the center of the ingot.

$\mathrm{V}$ located on both sides of primary $\mathrm{Al}_{3} \mathrm{~V}$ phases is precipitated with temperature dropping during the formation of primary $\mathrm{Al}_{3} \mathrm{~V}$ along the preferred orientation. As a result, the secondary dendrites of $\mathrm{Al}_{3} \mathrm{~V}$ phases are formed. The secondary dendrites grow quickly once high undercooling and enough $\mathrm{V}$ concentration distribution for the formation of $\mathrm{Al}_{3} \mathrm{~V}$ phases are present in front of the solidifying front. Even the tertiary 
dendrite can be found under these conditions above [Fig. 4]. The formation of the secondary dendrite is affected by cooling rate significantly. The number of the secondary dendrites on both sides of the primary dendrite grows largely and SDASs decrease with increasing of the cooling rate. Therefore, the SDASs of $\mathrm{Al}_{3} \mathrm{~V}$ phases formed in the copper mold are smaller than that located at the corresponding position of the ingot prepared in the graphite mold. Additionally, the SDASs of $\mathrm{Al}_{3} \mathrm{~V}$ phases at the edge of the ingot are also smaller than that in the center.

Only 0.58 wt. $\% \mathrm{~V}$ is dissolved into molten aluminum when the temperature drops to $736{ }^{\circ} \mathrm{C}$ and $\mathrm{V}$-containing phases will transfer from $\mathrm{Al}_{3} \mathrm{~V}$ phases into $\mathrm{Al}_{23} \mathrm{~V}_{4}$ phases on the basis of the Al-V binary equilibrium phase diagram shown in Fig. $7^{[9]}$. However, due to the fast cooling rates of the copper mold and graphite mold $\left(>24.3{ }^{\circ} \mathrm{C} \cdot \mathrm{s}^{-1}\right)$, there could be not enough time for the transformation from $\mathrm{Al}_{3} \mathrm{~V}$ to $\mathrm{Al}_{23} \mathrm{~V}_{4}$ in the molten aluminum. Similarly, there might be not enough time for the transformation to $\mathrm{Al}_{45} \mathrm{~V}_{7}$ phases at $688{ }^{\circ} \mathrm{C}$ and $\mathrm{Al}_{21} \mathrm{~V}_{2}$ (also designated $\mathrm{Al}_{10} \mathrm{~V}$ ) phases at $670{ }^{\circ} \mathrm{C}$ either. As a result, only $\mathrm{Al}_{3} \mathrm{~V}$ phases are present in the ingots prepared in both the copper mold and the graphite mold.

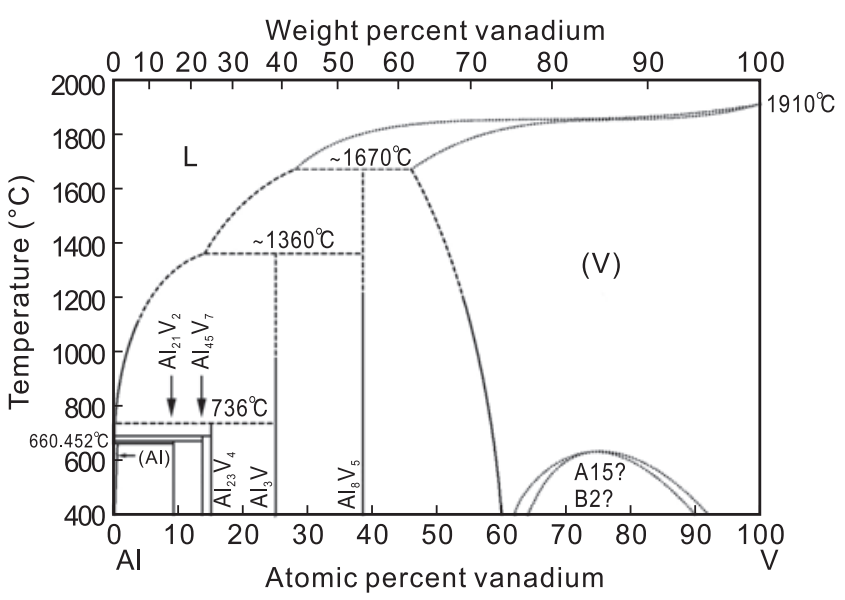

Fig. 7: Al-V binary phase diagram ${ }^{[9]}$

Low nucleation rates and disappearance of the preferred orientation result in the formation of coarse phases, when the cooling rate reduces to $2.0{ }^{\circ} \mathrm{C} \cdot \mathrm{s}^{-1}$ for the $\mathrm{Al}-10 \mathrm{wt} . \% \mathrm{~V}$ master alloy prepared in the refractory mold. So, there should be enough time for the transformation from $\mathrm{Al}_{3} \mathrm{~V}$ phases into other $\mathrm{V}$-containing phases, as a result of the formation of $\mathrm{Al}_{10} \mathrm{~V}$ phases with plate-like shape, as shown in Fig. 4 (c).

\subsection{Shapes of single $\mathrm{Al}_{3} \mathrm{~V}$ phase and $\mathrm{Al}_{10} \mathrm{~V}$ phase}

According to Figs. 4 and 6, although the distribution and the morphology of $\mathrm{Al}_{3} \mathrm{~V}$ phases are dendritic or arborization, the shape of single $\mathrm{Al}_{3} \mathrm{~V}$ phase can be considered as petal-like (almost without any angles). On the contrary, the shape of single $\mathrm{Al}_{10} \mathrm{~V}$ phase tends to be plate-like with more edges and corners as shown in Fig. 4 (c), and Figs. 6 (e) and (f).

Figure 8 shows the grain-boundary surface tensions at a junction of phases 1, 2 and 3. Three lines of Fig. 8 represent

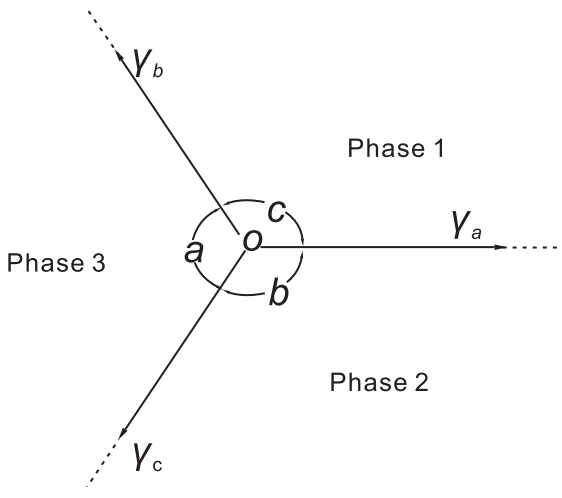

Fig. 8: Phase-boundary surface tensions at a junction of three phases

grain boundaries that lie perpendicular to the plane of the paper and meet in a line projection which is $o$. The three vectors $\gamma_{\mathrm{a}}$, $\gamma_{\mathrm{b}}$, and $\gamma_{\mathrm{c}}$ originating at point $o$ represent, by their directions and magnitudes, the surface tensions of the three boundaries. If these three force vectors are in static equilibrium, then the following relationship must be true as shown in Eq. (1) ${ }^{[15]}$ :

$$
\frac{\gamma_{\mathrm{a}}}{\sin a}=\frac{\gamma_{\mathrm{b}}}{\sin b}=\frac{\gamma_{\mathrm{c}}}{\sin c}
$$

where $a, b$ and $c$ are the dihedral angles between boundaries.

Figure 9 shows the phase boundary surface tensions at a junction between two phases A with a phase B. When the surface tensions in the boundaries are in static equilibrium, then Eq. (2) ${ }^{[15]}$ can be obtained:

$$
\gamma_{\mathrm{AA}}=2 \gamma_{\mathrm{AB}} \cos \frac{\theta}{2}
$$

where $\gamma_{\mathrm{AA}}$ is the surface tension in the single-phase boundary, $\gamma_{\mathrm{AB}}$ is the surface tension in the two-phase boundary, and $\theta$ is the dihedral angle between the two boundaries that separate the phase B from two phases A.

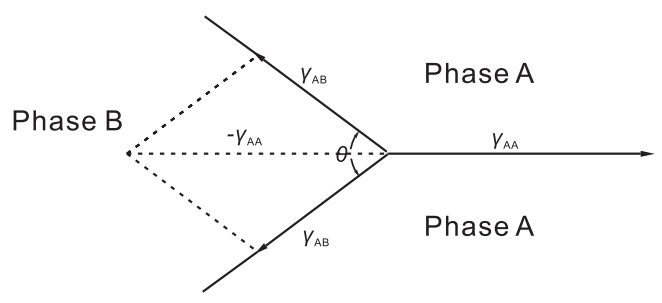

Fig. 9: Phase-boundary surface tensions at junction between two crystals of the same phase and two crystals of different phases

Since the $\mathrm{Al}_{3} \mathrm{~V}$ phase and $\mathrm{Al}_{10} \mathrm{~V}$ phase are formed at different times during the whole solidification process, their shapes largely depend on their surroundings at the moment of their formation. When the single $\mathrm{Al}_{3} \mathrm{~V}$ phase forms, its surrounding is filled with liquid. As a result, only two types of phases exist at that time: the liquid phase and $\mathrm{Al}_{3} \mathrm{~V}$ phase. So, the shape of the single $\mathrm{Al}_{3} \mathrm{~V}$ phase only is affected by liquid, just like the one shown in Fig. 9. Phases A and B can be considered as liquid phase and single $\mathrm{Al}_{3} \mathrm{~V}$ phase, respectively. Since no boundary exists in liquid, the value of $\gamma_{\mathrm{AA}}$ is zero. Based on Eq. (2), the dihedral angle $(\theta)$ should be $180^{\circ}$. So, the boundaries of $\mathrm{Al}_{3} \mathrm{~V}$ phases tend to 
be spherical shaped. As a result, with the combined effects of surface tension and fast solidification, the shape of $\mathrm{Al}_{3} \mathrm{~V}$ phase is petal-like (almost without any angle). Similarly, the single $\mathrm{Al}_{10} \mathrm{~V}$ phase is surrounded by both the liquid and $\alpha$-Al during solidification, so its shape is determined by the combined effects of the liquid phase and $\alpha-\mathrm{Al}$ phase. Since $\mathrm{Al}_{10} \mathrm{~V}$ phase forms at a very low cooling rate, the solidification process can be considered as equilibrium state. So, phases 1, 2 and 3 in Fig. 8 can be considered as $\mathrm{Al}_{10} \mathrm{~V}$ phase, liquid, and $\alpha-\mathrm{Al}$, respectively. Due to their interrelationships to maintain static equilibrium caused by the low cooling rate, none of the dihedral angles $(\mathrm{a}, \mathrm{b}$ and c) can reach up to $180^{\circ}\left(\sin 180^{\circ}=0\right)$ according to Eq. (1). As a result, the shape of $\mathrm{Al}_{10} \mathrm{~V}$ phase looks plate-like (mostly with angular shape).

\section{Conclusions}

V-containing phases with different types and morphologies are determined by the change of cooling rate during the solidification of Al-10 wt.\%V master alloys. The following conclusions can be drawn:

(1) Primary $\mathrm{Al}_{3} \mathrm{~V}$ phases with a dendritic pattern exist in the Al-10wt. $\% \mathrm{~V}$ master alloys when the ingots are cooled from $1,170{ }^{\circ} \mathrm{C}$ with the rates of $>24.3{ }^{\circ} \mathrm{C} \cdot \mathrm{s}^{-1}$, and the growth type is dendrite as well, while plate-like $\mathrm{Al}_{10} \mathrm{~V}$ phases are present when the cooling rate reduces to $2.0^{\circ} \mathrm{C} \cdot \mathrm{s}^{-1}$.

(2) When the cooling rate is $45.7^{\circ} \mathrm{C} \cdot \mathrm{s}^{-1}$ (copper mold), the average sizes of the first dendrite of $\mathrm{Al}_{3} \mathrm{~V}$ phases located at the edge and in the center of the ingot are $150.0 \mu \mathrm{m}$ and $190.0 \mu \mathrm{m}$, respectively, and their mean SDASs are $4.4 \mu \mathrm{m}$ and $9.8 \mu \mathrm{m}$, respectively. When the cooling rate is $24.3{ }^{\circ} \mathrm{C} \cdot \mathrm{s}^{-1}$ (graphite mold), the average sizes of the first dendrite of $\mathrm{Al}_{3} \mathrm{~V}$ phases are $275.0 \mu \mathrm{m}$ (edge) and $297.0 \mu \mathrm{m}$ (center), respectively, and their mean SDASs are $9.3 \mu \mathrm{m}$ and $9.5 \mu \mathrm{m}$, respectively. However, when the cooling rate reduces to $2{ }^{\circ} \mathrm{C} \cdot \mathrm{s}^{-1}$ (refractory mold), the plate-like $\mathrm{Al}_{10} \mathrm{~V}$ phases can be visible and their sizes located at the edge and in the center of the ingot are $93.2 \mu \mathrm{m}$ and 100.0 $\mu \mathrm{m}$, respectively.

\section{References}

[1] Chen Z G, Yang W L, Wang S Y, et al. Research Progress of Microalloyed Al Alloys. Rare Metal Materials and Engineering, 2010, 39(8): 1499-1504. (In Chinese)

[2] Wang $X$. The formation of $\mathrm{AlB}_{2}$ in an Al-B master alloy. Journal of Alloys \& Compounds, 2005, 403(1): 283-287.

[3] Maria T D G, Emanuela C, Daniele C, et al. The influence of $\mathrm{Ni}$ and $\mathrm{V}$ trace elements on high temperature tensile properties and aging of A356 aluminum foundry alloy. Metallurgical and Materials Transactions A, 2016, 47: 2049-2057.

[4] Lai J, Shi C J, Chen X G. Effect of $V$ addition on recrystallization resistance of 7150 aluminum alloy after simulative hot deformation. Materials Characterization, 2014, 96: 126-134.

[5] Shi C J, Chen X G. Effect of vanadium on hot deformation and microstructural evolution of 7150 aluminum alloy. Materials Science and Engineering A, 2014, 613: 91-102.

[6] Shi C J, Chen X G. Evolution of activation energies for hot deformation of 7150 aluminum alloys with various $\mathrm{Zr}$ and $\mathrm{V}$ additions. Materials Science and Engineering A, 2016, 650: 197-209.

[7] Shi C J, Chen X G. Effects of $Z r$ and V micro-alloying on activation energy during hot deformation of 7150 aluminum alloys. Springer International Publishing, 2015, 5: 163-167.

[8] Shi C J, Chen X G. Hot Workability and Processing Maps of 7150 Aluminum Alloys with $\mathrm{Zr}$ and $\mathrm{V}$ Additions. Journal of Materials Engineering \& Performance, 2015, 24(5): 1-14.

[9] Murray J L. Al-V (aluminum-vanadium). Bulletin of Alloy Phase Diagrams, 1989, 10(4): 351-357.

[10] Elhadari H A, Patel H A, Chen D L, et al. Tensile and fatigue properties of a cast aluminum alloy with $\mathrm{Ti}, \mathrm{Zr}$ and $\mathrm{V}$ additions. Materials Science and Engineering A, 2011, 528: 8128-8138.

[11] Meng $Y$, Cui $J$ Z, Zhao $Z \mathrm{H}$, et al. Effect of vanadium on the microstructures and mechanical properties of an Al-Mg-Si-CuCr-Ti alloy of $6 \mathrm{XXX}$ series. Journal of Alloys \& Compounds, 2013, 573(3): 102-111.

[12] Meng Y, Cui J Z, Zhao Z H, et al. Study on Microstructures of Al4wt.\%V Master Alloys. Metallurgical \& Materials Transactions A 2014, 45(9): 3741-3747.

[13] Carlson O N, Kenney D J, Wilhelm H A. Aluminum-Vanadium System. Trans. ASM, 1953, 47: 520-542.

[14] Cui Z Q, Qin Y C. Metallurgy and Heat Treatment, 2nd ed. Beijing: China Machine Press, 2011: 52-53. (In Chinese)

[15] Robert E R. Physical Metallurgy Principles, 3rd ed. Bangalore: Eastern Press Pvt. Ltd., 1991: 185-187.

This work was financially supported by the Electromagnetic Processing of Materials (EPM) Lab Foundation in Northeastern University in China (No. NEU-EPM-005), the National Natural Science Foundation of China (Nos. 51374067 and 51804010), and the Training Program Foundation for the Talents by Beijing (No. 2015000020124G023). 